\title{
11th International Congress on Amino Acids, Peptides and Proteins
}

Vienna, Austria

August 3-7, 2009

President: Gert Lubec, Austria 
In search for new targets for antimalarials we have investigated the biosynthesis of hypusine present in eukaryotic initiation factor (eIF$5 \mathrm{~A}$ ), in particular the deoxyhypusine synthase (DHS), and eIF-5A from the different human malaria parasites $P$. falciparum and $P$. vivax. We now describe the cloning and expression of deoxyhypusine hydroxylase (DOHH), the enzyme that completes the modification of eIF-5A through hydroxylation. The sequence of the dohh cDNA revealed an open reading frame of 1,236 bp encoding a protein of 412 amino acids with a calculated molecular mass of $46.45 \mathrm{kDa}$ and an isoelectric point of 4.96. Interestingly, DOHH from Plasmodium has a FASTA SCORE of only 27 compared to its human ortholog and contains several matches similar to E-Z type HEAT-like repeat proteins (IPR004155) (InterPro), PF03130 (Pfam), SM00567 (SMART) present in phycocyanin lyase subunits of cyanobacteria. Expression of DOHH in E. coli resulted in a signal of $42 \mathrm{kDa}$ in SDS PAGE analysis. The purified protein displayed hydroxylase activity in a novel in vitro DOHH assay. In contrast, phycocyanin lyase activity was absent.

The dohh gene is present as a single copy gene in the genome of Plasmodium and is transcribed in both developmental stages. The Nterminus of Plasmodium DOHH contains a signal peptide which might direct the protein to a different cellular compartment.

\section{Biogenic polyamines: the structural variable}

M. P. M. Marques ${ }^{1,2}$, A. M. Amorim da $\operatorname{Costa}^{1}$, J. Tomkinson ${ }^{3}$, R. Calheiros ${ }^{1}$, and L. A. E. Batista de Carvalho ${ }^{1}$

1 "Molecular Physical-Chemistry", R\&D Unit, University

of Coimbra, Coimbra, Portugal

${ }^{2}$ Biochemistry Department, University of Coimbra, Coimbra,

Portugal

${ }^{3}$ ISIS Facility, The Rutherford Appleton Laboratory, Chilton, UK

Biogenic polyamines-putrescine ( $\mathrm{PUT}, \mathrm{H}_{2} \mathrm{~N}\left(\mathrm{CH}_{2}\right)_{4} \mathrm{NH}_{2}$ ), spermidine (SPD, $\left.\mathrm{H}_{2} \mathrm{~N}\left(\mathrm{CH}_{2}\right)_{3} \mathrm{NH}\left(\mathrm{CH}_{2}\right)_{4} \mathrm{NH}_{2}\right)$, spermine (SPM, $\mathrm{H}_{2} \mathrm{~N}\left(\mathrm{CH}_{2}\right)_{3}$ $\mathrm{NH}\left(\mathrm{CH}_{2}\right)_{4} \mathrm{NH}\left(\mathrm{CH}_{2}\right)_{3} \mathrm{NH}_{2}$ ) or agmatine (AGM, $\mathrm{NH}_{2}-\mathrm{CH}_{2}-\mathrm{CH}_{2}-\mathrm{CH}_{2}-$ $\mathrm{CH}_{2}-\mathrm{NH}-\mathrm{C}\left(-\mathrm{NH}_{2}\right)(=\mathrm{NH})$ ) - are ubiquitous in cells of higher organisms and fundamental characters in processes essential to life as cell growth and differentiation, through tightly regulated concentrationdependent routes. MGBG (methylglyoxal bis(guanylhydrazone)), for instance, is a competitive inhibitor of $S$-adenosyl-L-methionine decarboxylase, therefore involved in the biosynthesis of SPD and SPM.

The activity of a biologically relevant compound, however, does not rely solely on its chemical properties, but it is also dependent on its conformational preferences, that must be accurately determined for a thorough understanding of its function and mechanisms of action.

The present report describes the conformational analysis of PUT, SPD, SPM and AGM, as well as of MGBG, through quantum mechanical calculations coupled to vibrational spectroscopy techniques (infrared, Raman and Inelastic Neutron Scattering).

The conformational preferences of this kind of alkylamines, comprising different protonation sites, are ruled by their biochemical environment (i.e. $\mathrm{pH}$, type of tissue and nearest biomolecules or receptors). They rely on a balance between the formation of stabilising intramolecular $(\mathrm{N}) \mathrm{H}$ : $\mathrm{N}$ and/or $(\mathrm{C}) \mathrm{H}$ : $\mathrm{N}$ hydrogen-bonds, and the minimisation of steric and electrostatic repulsive interactions. Under physiological conditions, polyamines occur are either totally protonated, natural polycations, or as partially ionised species (in particular situations).

The establishment of these highly sensitive structure-activity relationships allows to achieve a better understanding of polyamines' particular biological roles, and to predict mechanisms for their transport and mode of action.

Acknowledgments: MPMM, AMAC and LAEBC acknowledge financial support from FCT (PTDC/QUI/66701/2006).

\section{Delivering anti-cancer agents to human leukaemic cells via polyamine transport system}

Heather M. Wallace ${ }^{1}$, Radiah A. Ghani ${ }^{1}$, Andrew J. Palmer ${ }^{1}$, Navneet Kaur ${ }^{2}$, and Otto Phanstiel ${ }^{2}$

${ }^{1}$ Department of Applied Medicine, University of Aberdeen, UK

${ }^{2}$ Department of Chemistry, University of Central Florida,

Orlando, FL, USA, h.m.wallace@abdn.ac.uk

One of the big challenges to oncology is to deliver cytotoxic agents selectively to cancer cells. Currently, the lack of selectivity has limited the clinical use of many of the available drugs. By enhancing specific cell targeting, non-specific toxicities can be minimised. By taking advantage of the highly active polyamine uptake system (PTS) in tumour cells we have developed a novel way to deliver polyaminedrug conjugates selectively to cancer cells. The PTS is relatively non specific and does not differentiate between natural polyamines and structural analogues and so can accommodate a range of polyamine conjugates. Using this delivery system, chemotherapeutic drugs attached to a polyamine chain can be targeted to tumour cells via selective uptake and at the same time the toxic effects on normal cells can be decreased. A series of novel compounds, which include a DNA intercalator, anthracene, with a polyamine side chain have been synthesized.

The cytotoxicity of two compounds, namely 9-anthracenylmethyl-butanediamine (Ant 4), $\mathrm{N}^{1}$-anthracenylmethyl-4,4triamine (Ant 4,4$)$, was investigated as a paradigm for the delivery of cytotoxic agents via PTS using human leukaemic cells (HL-60) as in vitro model. The compounds showed significant toxicity and apoptosis. An interesting finding was the significant polyamine depletion caused by treatment with both compounds after $48 \mathrm{~h}$ exposure. Indirect methods were used to show that the conjugates used the PTS.

In summary, the preliminary data indicate the Ant 4 and Ant 44 recognise and utilise the PTS. This means of drug delivery via PTS represents a promising approach for therapies in cancer.

\section{Prognostic value of erythrocyte polyamine levels in renal cell carcinoma patients. A prospective analysis in 418 cases}

P. Bigot ${ }^{1}$, K. Bensalah ${ }^{1}$, N. Rioux-Leclercq ${ }^{2}$, F. Guillé ${ }^{1}$, B. Lobel ${ }^{1}$, J.-P. Moulinoux ${ }^{3}$, V. Catros-Quemener ${ }^{3}$, B. Cipolla ${ }^{3,4}$, and J.-J. Patard ${ }^{1}$

${ }^{1}$ Urology, CHU Rennes, France

${ }^{2}$ Pathology, CHU Rennes, France

${ }^{3}$ URA CNRS 1529, University of Rennes I, France

${ }^{4}$ CHP St Grégoire, Rennes, France

Introduction: Erythrocyte polyamines (EPA) Spermidine (Spm) and Spermine $(\mathrm{Spm})$, are of prognostic interest in prostate carcinoma. We have assessed the value of EPA as prognostic markers in renal cell carcinoma patients. 